\title{
Gangliosides and autoimmune neuropathies: classification and clinical aspects of autoimmune neuropathies
}

\author{
Andreas J Steck, Ludwig Kappos
}

\begin{abstract}
The aim of this short review is to provide some background information on the subject of antibodies to gangliosides and peripheral neuropathies. Gangliosides are a family of acidic glycolipids composed of a lipid (ceramide) and carbohydrate (oligosaccharide chain). Four gangliosides GM1, GDla, GD1b and GT1b, are especially abundant in the brain. They each contain an identical four sugar chain but vary in the number of sialic acid molecules. In the peripheral nerve, a fifth ganglioside, LM1, containing a different carbohydrate structure occurs in relative abundance. Gangliosides are present in the membrane of neurons, on the axolemma, particularly at the node of Ranvier and to some extent also in myelin. They are synthesised in the Golgi apparatus, transported down the axons at fast rates of axoplasmic flow to become inserted in the axolemma and at synaptic terminals. In addition to gangliosides, other glycoconjugates are found in the peripheral nerve including neutral glycolipids, glucuronic acid containing glycolipids, and glycoproteins such as myelin associated glycoprotein (MAG) and the myelin glycoproteins Po and PMP22. ${ }^{1}$ Most of these glycoconjugates have been implicated in the past as being candidate antigens in instances of peripheral neuropathy in which antibodies to one or more of these compounds may be measured. ${ }^{2}$ Whether these antibodies are pathogenic alone, or there are some associated factors necessary to cause the neuropathy, is a matter of considerable debate.
\end{abstract}

\section{Peripheral neuropathies and neuropathic processes}

The primary neural elements that compose the peripheral nervous system lie partly within the central nervous system, particularly the cell bodies of motor neurons and the intra spinal portion of the central processes of primary sensory neurons. ${ }^{3} \mathrm{~A}$ part of these elements therefore are protected by the blood-brain-barrier. Other portions lie behind the more permeable blood-nerve-barrier and finally, the dorsal root ganglia themselves and some motor nerve terminals at the neuromuscular junction are barrier free. These anatomical facts have important implications for distribution of disease and selective vulnerabilities.

The two major processes by which peripheral nerve fibres are affected are segmental demyelination and axonal degeneration. Primary breakdown of myelin is the hallmark of segmental demyelination. The process usually begins at a node of Ranvier by paranodal involvement. The physiological consequence of segmental demyelination is conduction block. Other pathophysiological features of demyelinating neuropathies are the slowing of nerve conduction velocities, prolonged distal latencies, and late responses. Onset and recovery from segmental demyelination can be rapid and dramatic as in the case of acute Guillain-Barré syndrome. However, in primary demyelinating neuropathies associated with dysproteinaemia, demyelination occurs at a much slower pace. Both conditions are thought to be of autoimmune origin, and differences in the rate of progression must be due to some as yet poorly understood autoimmune factors. Axonal degeneration usually results from dysmetabolic events affecting the lower motor neuron or primary sensory neuron. The sites of greatest vulnerability appear to be those furthest from the nerve cell body. In some neuropathies mixtures of axonal degeneration and segmental demyelination occur.

\section{Peripheral neuropathies and anti-glycoconjugate antibodies} A) BACKGROUND

Several findings serve as background. Different authors have reported the association of peripheral neuropathy and monoclonal proteins and in some patients it was shown that the monoclonal protein bound to peripheral nerve. In 1982 Braun et $\mathrm{al}^{4}$ showed that the structure to which the monoclonal IgM was bound was myelin associated glycoprotein (MAG) and since then many more such patients have been identified. ${ }^{5}$ Soon after, it was observed that the IgM bound to the carbohydrate part of MAG. The epitope for monoclonal IgM of patients is also present on two glycosphingolipids present in peripheral nerve and is referred to as SGPG and SGLPG. In addition Po, another glycoprotein of myelin, also carries the epitope. ${ }^{6}$ Current evidence strongly suggests a causative role for the anti-MAG antibodies in the demyelinating neuropathy.

Interest in autoantibody activities of monoclonal proteins was stimulated by the finding that some patients with lower motor neuron syndromes had monoclonal antibodies 
binding to one or more gangliosides. In addition, many patients with multifocal motor neuropathies have high titres of polyclonal antibodies to the ganglioside GM1. ${ }^{7}$ More recently, elevated antibodies to the ganglioside $\mathrm{Gq} 1 \mathrm{~b}$ have been shown in patients with Miller Fisher syndrome. ${ }^{8}$ The controls, including those with Guillain-Barré syndrome, were negative. Taken together, these observations suggest the possibility that glycoconjugates (glycoproteins and/or glycolipids) could play a role in the immunopathogenesis of autoimmune neuropathies.

B) MOTOR NEURON DISEASE

Separating motor neuron diseases from pure motor neuropathies has not always been easy. For example, is it correct to call a condition in which there is loss of anterior horn cells a motor neuropathy or should it be designated as a motor neuron disease? There are clearly problems in deciding, on clinical and electrophysiological grounds, whether a condition is a motor neuronopathy or an axonopathy or both. ${ }^{9}$

The report of Freddo et $a l^{10}$ has triggered a number of surveys on the relation of motor neuron disease and anti-ganglioside GM1 antibodies. A few patients with motor neuron syndromes have a monoclonal IgM reactivity with gangliosides, typically GM1 and Gd1b. Some patients with the clinical course and features of classic amyotrophic lateral sclerosis also have high titres of antibodies (usually polyclonal) to gangliosides. ${ }^{112}$ At present the meaning of these observations is unclear.

\section{C) MULTIFOCAL MOTOR NEUROPATHY}

In the last five years, an increasing number of patients have been described with a clinical syndrome of asymmetric motor weakness, electrophysiological evidence of motor conduction block as well as axonal loss. Some of these patients have been shown to have polyclonal anti-GM1 antibodies in high titres. These patients are clearly distinct from classical motor neuron diseases or ALS in terms of clinical signs, symptoms, and response to treatment. Many publications have now shown that these patients are responsive either to courses of intravenous cyclophosphamide or intravenous immunoglobulin. ${ }^{13-15}$

D) DEMYELINATING NEUROPATHY WITH MONOCLONAL IGM ANTI-MAG ANTIBODY More than $50 \%$ of patients with IgM neuropathy have an anti-MAG reactivity. The phenotype of this neuropathy tends to be that of a large fibre sensory neuropathy with ataxia and demyelinating features by electrodiagnostic examination. Additional reasons for considering this neuropathy a separate clinical entity are:

1) In contrast to IgG and IgA neuropathy those with anti-MAG antibodies show immunoglobulin deposits on myelin in nerve biopsy. ${ }^{17}$

2) Abnormal widening of myelin lamellae is almost pathognomonic for patients with antiMAG antibodies. ${ }^{17}$
3) The clinical characteristics, course, electromyographic features for anti-MAG neuropathy, differ statistically from those with IgG or IgA MGUS neuropathy.

In general it has been claimed that patients with IgG and IgA paraproteins respond better to corticosteroids, cytotoxic drugs or plasma exchange than those with $\operatorname{IgM}$ paraprotein. Results of a double-blind trial confirmed this impression: plasma exchange was efficacious in neuropathy with monoclonal gammopathy of undetermined significance (MGUS) of the IgG or IgA type, but not in the IgM group. It is not known why patients with IgM gammopathy do not respond, but plasma exchange may not have been effective in removing IgM antibodies from the site of the action in the myelin sheath in the time allowed by the study design. ${ }^{18}$

\section{Conclusion}

The subject of polyneuropathies associated with antibodies that bind to glycoconjugates has generated a wealth of publications. Many different autoantibodies have now been described in association with peripheral nerve disorders. It is interesting that neuropathies caused by these different autoantibodies appear to be clinically distinct. Autoantibodies to MAG cause a demyelinating sensory motor neuropathy. Autoantibodies to the ganglioside GM1 have been associated with a multifocal motor neuropathy but other motor syndromes have also been described in the presence of anti-GM1 antibodies. In Miller Fisher syndrome elevated antibodies to the ganglioside $\mathrm{Gq} 1 \mathrm{~b}$ have been reported. This suggests that antibodies to glycolipids or glycoproteins are important factors in the pathogenesis of neuropathies.

However, some problems remain: progress in understanding the pathogenesis of these autoantibodies has been slow because of the lack of appropriate animal models. The reliability of antibody measurement used by different investigators has been questioned and results obtained in different laboratories are not easily comparable. ${ }^{19}$ As antibodies to gangliosides seem to be ubiquitous and part of the normal immune repertoire, the significance of low titre antibodies to various glycoconjugates that are found in some cases of GBS, motor neuron diseases and chronic inflammatory demyelinating polyneuropathy is a matter of debate. Whether antibody responses are secondary to neural tissue breakdown is not known, although the absence of high titres in patients with other neurological diseases associated with neuronal tissue breakdown is an argument against this assumption..$^{20}$ The vexing problem is the discovery of other cases of the same disease that do not have any measurable antibody titre to glycoconjugates. Answers to all these questions may have to wait for a better understanding of the underlying autoimmune mechanisms.

This study was supported by the Swiss National Science Foundation and the Swiss Multiple Sclerosis Society. 
1 Latov N. Antibodies to glycoconjugates in neurological disease. Clinical Aspects of Autoimmunity 1990;4:19-29.

2 Steck AJ. Inflammatory neuropathy: pathogenesis and clinical features. Curr Opin Neurol Neurosurg 1992;5: clinical

3 Bouche P, Vallat JM (ed). Neuropathies périphériques. Paris: Doin, 1992.

4 Braun PE, Frail DE, Latov N. Myelin associated glycoprotein is the antigen for monoclonal IgM in polyneuropathy. $f$ Neurochem 1982;39:1261-5.

5 Steck AJ, Murray N, Dellagi K, Brouet JC, Seligmann M Peripheral neuropathy associated with monoclonal IgM autoantibody. Ann Neurol 1987;22:764-7.

6 Bollensen E, Steck AJ, Schachner M. Reactivity with the peripheral myelin glycoprotein $P o$ in serum from patients with monoclonal IgM gammopathy and patients with mouropathy. Neurology 1988;38:1266-70

7 Pestronk A. Invited review: motor neuropathies, motor neuron disorders, and anti-glycolipid antibodies. Muscle Nerve 1991;14:927-36.

8 Chiba A, Kusunoki S, Shimizu T, Kanazawa I. Serum IgG antibody to ganglioside $\mathrm{Gq} 1 \mathrm{~b}$ is a possible marker of Miller Fisher syndrome. Ann Neurol 1992;31:677-9.

9 Rowland LP. Motor neuron diseases and motor neuropathy. Curr Opin Neurol Neurosurg 1991;4:699-706.

10 Freddo L, Yu RK, Latov N, et al. Gangliosides GM $_{1}$ and GDlb are antigens for IgM M-protein in a patient with motor neuron disease. Neurology 1986;36:454-8.

11 Pestronk A, Adams RN, Clawson L, Cornblath D, Kuncl RW, Griffin D, Drachman DB. Serum antibodies to GM, Griffin D, Drachman DB. Serum antibodies to $\mathrm{GM}_{1}$ ganglioside in amy
Neurology 1988;35:1457-61.

12 Adams D, Kuntzer T, Bunger D, Chofflon M, Magistri MR, Regli F, Steck AJ. Predictive value of anti-GM ganglioside antibodies in neuromuscular diseases: study of 180 sera. $\mathcal{F}$ Neuroimmunol 1991;32:223-30.

13 Feldmann EL, Bromberg MD, Albers JW, Pestronk A Immunosuppressive treatment in multifocal motor neuropathy. Ann Neurol 1991;30:397-401.

14 Kaji R, Shibasaki H, Kimura J. Multifocal demyelinating motor neuropathy: Cranial nerve involvement and immunoglobulin therapy. Neurology 1992;42:506-9.

15 Nobile-Orazio $E$, Marbieri S, Carpo $M$ Scarlato G. High-dose intravenous immunoglobulin therapy in multifocal motor neuropathy. Neurology 1993,

16 Kaji R, Oka N, Tsuji T, Mezaki T, Nishio T, Akiguchi I, Kimura J. Pathological findings at the site of conduction block in multifocal motor neuropathy. Ann Neurol 1993;33:152-8

17 Vital A, Vital C, Julien J, Baquey A, Steck AJ. Polyneuropathy associated with IgM monoclonal gammopathy. Immunological and pathological study in 31 patients. Acta Neuropathol 1989;79:160-7.

18 Dyck PJ, Low PA, Windebank AJ, et al. Plasma exchange in polyneuropathy associated with monoclonal gammopathy of undetermined significance. $N$ Engl $f$ Med 1991; 325:1482-6.

19 Marcus DM, Latov N, Hsi BP, Gillard BK. Measurements and significance of antibodies against $\mathrm{GM}_{1}$ ganglioside. Report of a workshop, 18 April 1989, Chicago, IL, USA. $₹$ Neuroimmunol 1989;25:255-9.

20 Sadiq SA, Thomas FP, Kilidireas K, et al. The spectrum of neurologic disease associated with anti-GM $\mathbf{G M}_{1}$ antibodies. Neurology 1990;40:1067-72.

21 Steck AJ, Adams D. Motor neuron syndromes and monoclonal IgM antibodies to gangliosides. In: Rowland LP, ed. Advances in Neurology, vol 56: Amyotrophic lateral sclerosis and other motor neuron diseases. New York: Raven Press, 1991.

22 Nobile-Orazio E, Manfredini E, Carpo $\mathbf{M}$, et al. Neuropathy and IgM monoclonal gammopathy: $M$ Protein specificity and Neuropathy features in 70 Protein specificity and Neurop

23 Pestronk A, Zhu S, Feldman EL, Arbor A. A distinctive pattern of serum IgM reactivity to $\mathrm{GM}_{1}$ ganglioside and cyclophilin in multifocal motor neuropathy (MMN) Neurology 1992;42(Suppl 3):177.

24 Kinsella LJ, Lange DJ, Latov N, Trojaborg W, Lovelace RE, Rowland LP. Clinical and electrophysiological correlates of abnormal $\mathrm{GM}_{1}$ antibody titers. Neurology 1992;42(Suppl 3):177. 